analysis is not possible due to the lack of income inequality data on the same countries in both of the time periods analyzed.

${ }^{14}$ Due to problems of data availability, it was neither possible to lag all measurements nor to collect data for three years, among which the mean would be taken on all of the independent variable measurements. The exceptions to the research design are as follows. Debt data for the first cohort of countries are from 1971. In the first cohort of countries, foreign investment data from the year 1967 were used for the following countries: Argentina, Chile, Colombia, Costa Rica, Ecuador, El Salvador, Gabon, Ghana, Guatemala, Honduras, India, Ivory Coast, Kenya, Mexico, Nicaragua, Pakistan, Philippines, Senegal, Sierre Leone, Sudan, Tunisia, and Venezuela. Foreign investment data from the years 1967 and 1968 were used for Brazil. Foreign investment data from the year 1970 were used for India. Political democracy data for the year 1972 were used for all countries in the first cohort. In the second cohort, Ghana's trade data are from the years 1980, 1981, and 1982.

${ }^{15}$ The variables involved in the polynomial equation (LOGDP and LOGDPSQ) by their very nature are, however, highly collinear.

${ }^{16} \mathrm{Although}$ the sample in this study is not random, significance levels are reported because they are good indicators as to whether the estimated effects are large enough to be considered empirically important.

${ }^{17}$ In the split analysis I accepted coefficients as statistically significant at the .10 level, given that small samples cause conservative significance tests (Winkler and Hays 1975).

\section{Testing a Model of American Elite Generational Continuity with Cross National Data}

\author{
DONN M. KURTZ II \\ University of Louisiana at Lafayette
}

\section{Abstract}

\begin{abstract}
$A$ cross national data set consisting of 122 national chief executives who were in office in 1990 is used to test the validity of a model of American elite generational continuity. The bypoth. esis is that the model will be as useful in explaining the kinship dimensions of elite continuity in other political systems as it is in the study of American political leadership. In broad terms the findings with respect to national chief executives correspond closely to the expectations of the model. Most of the differences between the expected and the discovered kinship patterns may be accounted for by the fact that descendants of at least some of the leaders still have time to enter the political arena.
\end{abstract}

As the United States approaches the formal beginning of the presidential election of 2000 , the four leading contenders represent a continuing characteristic of American politics; they are all the product of politically active or public families. Governor George W. Bush is the son of a president and the grandson of a senator; Vice President Al Gore, the son of another senator; and Senator John McCain, the son and grandson of full admirals. Former Senator Bill Bradley is from a family with at least three previous generations of local political leadership. These candidates are not unique; instead they are current examples of an established pattern of extensive family involvement in American politics documented most recently in a study of state and national supreme court justices which included a three generational model of elite continuity to explain this phenomenon (Kurtz 1997b). 
The objective of this paper is to employ that American model to analyze the kinship connections of a totally different group of political leaders, the chief executives of over a hundred-twenty political systems. The hypothesis is that the model will be as useful in explaining the familial dimensions of elite continuity in other countries as it is in the study of the United States, and that it will reveal notable cross national similarities in this aspect of elite recruitment and structure.

The model (see Figure I) indicates the expected linkages between the members of a set of political figures and their office-holding relatives in the previous and in the subsequent generations as well as the member's own generation. Political leaders may be categorized as either beirs or newcomers, terms which correspond to Kenneth Prewitt's distinction between the socialized and the mobilized $(1979,59)$. In turn those two groups can be further subdivided according to the office-holding characteristics of their relatives. Heirs are either transmitters, or maintainers. Transmitters have both ancestors and descendants in office; they inherit a family political tradition and pass it on to the next generation. Those who inherit a political legacy but do not transmit it to the next generation are maintainers. Newcomers represent the first generation in their families to have held office and they can be divided into three subtypes. Founders initiate a pattern of family political activity and they have descendants who continue the families' public involvement while a contemporary has politically oriented relatives of the same generation. Finally, the unconnected have no politically active kinsmen.
Figure 1: A Model of Elite Generational Continuity

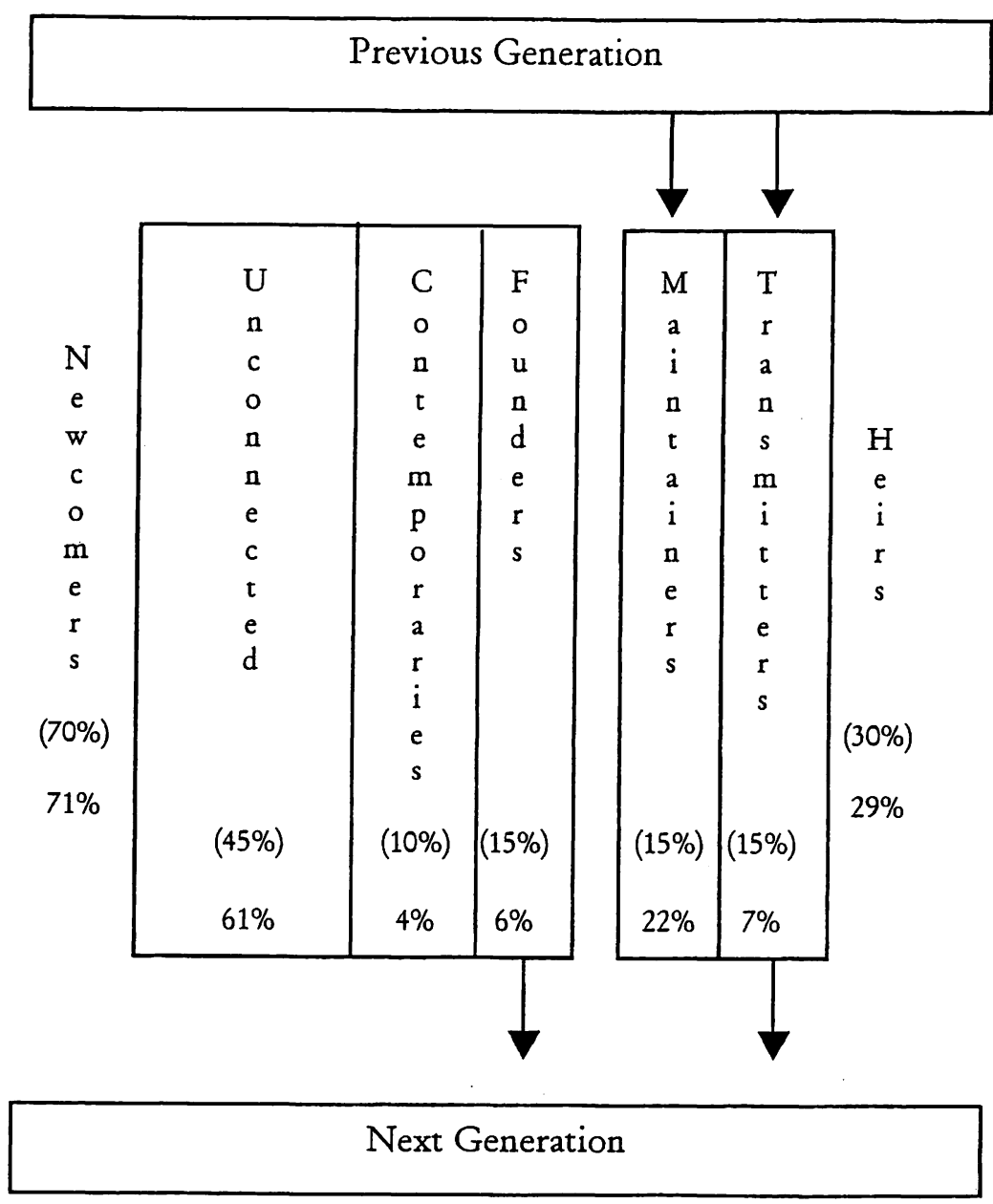

The numbers in parentheses in the figure indicate the expected percentages of any group of American leaders who will be classified as either newcomers or heirs. It also predicts how newcomers and heirs will fit into one of the subcategories discussed above. To test the validity of the model the author developed a small data set consisting of the nine presidents who served from 1933 through 1988. The results with respect to the presidency (see 
Table 1) were fairly close to the predicted results and provided initial support for the accuracy of the model (Kurtz 1997b, 96).

Table 1

Generational Types: Expected Distribution, U. S. Presidents, and World Executives

\begin{tabular}{|c|c|c|c|}
\hline Generational Type & $\begin{array}{c}\text { Expected } \\
\text { Distribution }\end{array}$ & $\begin{array}{c}\text { U.S. } \\
\text { Presidents } \\
1933-1988\end{array}$ & $\begin{array}{c}1990 \\
\text { Chief } \\
\text { Executives }\end{array}$ \\
\hline Total Heirs & $30 \%$ & $33 \%$ & $29 \%$ \\
\hline Maintainers & $(15 \%)$ & $(11 \%)$ & $(22 \%)$ \\
\hline Transmitters & $(15 \%)$ & $(22 \%)$ & $(7 \%)$ \\
\hline Total Newcomers & $70 \%$ & $67 \%$ & $71 \%$ \\
\hline Founders & $(15 \%)$ & $(22 \%)$ & $(6 \%)$ \\
\hline Contemporaries & $(10 \%)$ & $(11 \%)$ & $(4 \%)$ \\
\hline Unconnected & $(45 \%$ & $(33 \%)$ & $(61 \%)$ \\
\hline (number of cases) & $(9)$ & $(122)$ & \\
\hline
\end{tabular}

To determine the appropriateness of the model to other political systems, data were compiled on the office holding characteristics of the families of national chief executives in office in 1990. These political figures were the effective heads of government in all states listed in The World Fact Book 1990. States with a population of less than 500,000 and ones in which the effective head of government was an hereditary monarch were not included. A total of 122 cases are included in the data and forty-seven (39\%) of them had at least one office-holding kinsman. The numbers not enclosed in parentheses in the figure indicate where the executives fit in the model.

In broad terms the findings with respect to national chief executives correspond closely to the expectations of the model which predicts that $30 \%$ of any set of political leaders will have inher218 ited a propensity toward public life from an ancestor in the immediately preceding generation. Among national leaders that rate of inheritance is $29 \%$. Similarly, the model suggests that $70 \%$ of leaders will be the first in their families to have held office; our findings are that $71 \%$ of the executives are newcomers.

The kinship patterns of chief executives deviate from the expected when examining the two specific types of inheritors and the three categories of newcomers. Among heirs, there are fewer transmitters than expected and the new members include fewer founders and contemporaries. Those deviations from the expected obviously create a final difference; those leaders with no relatives, the unconnected, should constitute $45 \%$ of the total but in fact are $61 \%$ of all executives.

Most of the differences between the expected and the discovered kinship patterns may be accounted for by the fact that descendants of at least some of the leaders still have time to enter the political arena; it is not accurate to conclude that the political experience of the next generation is completely accounted for. As of August 1998, fifteen chief executives had descendants in office; that number will certainly increase. Second generation public officials could come from three of the generational types, and any subsequent political activity by that generation would result in greater correspondence to the model. Those who now have no relatives in politics may yet see their children enter the arena. Similarly, those who are now categorized as maintainers or contemporaries could still transmit their political legacy to the next generation. It is possible that more descendants are already in politics than are reported here. Finding information about a prominent official's ancestry is easier than developing a profile of that person's descendants (see Kurtz 1997a, 65).

Support for the prediction of future political activity on the part of descendants is found in other studies suggesting that high political office creates a political legacy which eventually will be 
used by descendants of those officials. Over a third of the members of the Louisiana and United States supreme courts had office-holding relatives in one or more of three descending generations (Kurtz 1997b, 83). Similarly, more than three quarters of all American presidents had politically active children and twentynine percent (two of seven) of the most recent presidents already have children in politics (Kurtz 1997a, 73).

The model is intended to indicate only the generational patterns of political activity of relatives of a particular elite; it suggests nothing about who the kinsmen are, the size of the families, or the offices held. Understanding those dimensions of the data requires further analysis. Over $80 \%$ of the 47 kin-connected executives had a close relative (parent, child, and \or a sibling) in public office. The thirty-four heads of government who are heirs had 48 kinsmen predecessors including 27 parents, 12 uncles, and 6 fathers-in-law. Almost three fourths of the inheritors followed in the political footsteps of a parent. Half of the twenty-two descendant-politicians are children of chief executives including eight sons and three daughters. In addition there are nine sonsin-law and two nephews.

The category contemporary is somewhat misleading in that it undercounts the actual number of intra generational connections. An executive is considered a contemporary if his only relatives are of the same generation. However, transmitters, maintainers, and founders may also have siblings and cousins in office. In addition to the five cases classified as contemporaries in the figure, there are an additional 14 instances of connections within the executives' own generation. Thus the families of $19(16 \%)$ of the chief executives contribute to intra generational elite unity and most of those linkages are between siblings.

The forty-seven kin-connected executives have more than twice the number of office-holding kinsmen than minimally necessary given the actual number of cases in each of the categories in the model. The results reported here necessitate 55 relatives. Thirtynine maintainers, founders, and contemporaries need have but one politically active relative while the eight transmitters require two (one ancestor and one descendant) for a total of 55. In fact the officials in question have 123 relatives, over half of whom held a major office including thirteen as chief executives. Thirteen of those kinsmen are not represented in the model because they are grandparents or great grandparents. Eight executives had a grandparent in office; one had a great grandparent; and two had both. As a consequence of that larger number of kinsmen, the connections between and within generations are more extensive than the percentages in the figure reveal.

Several observations may be drawn from this analysis. First, at the very minimum, the model offers a useful framework for comparative analysis. Elites from different systems, regions or historical periods can be compared and contrasted in terms of their conformity to the model. Second, the research demonstrates that a model developed to study attributes of American elites has validity in a cross national context. Data on national chief executives from 122 countries generally adhere to the expectations of the model. The implication of this conclusion is that the patterns of family political activity identified in the United States are universal. Finally, the model is multidimensional; it calls attention to an elite's connections to ancestors, descendants, and contemporaries. Unlike most studies which document only parental political activity, this approach places the political leaders in a more comprehensive kinship setting. The result is a more accurate understanding of the prevalence of many forms of kinship connections. 


\section{Notes}

1. I have changed some of the terminology from the original presentation but there is no change in the substance of the model. Two additional concepts, relative and public office, are central to the model and require precise definition. Relatives in all three generations may be consanguineous or affinal. In the preceding generation these possibilities include parents, uncles or aunts (by blood or marriage), parents-in-law, and first cousins once removed. Relatives in the same generation include siblings, cousins, and spouses of siblings. Finally, descendants could be children, nieces and nephews, the spouses of children, and first cousins once removed. The definition of the synonymous concepts politically active, office-bolder, and public office used in the context of American families included only formal governmental and party positions (Kurtz 1989, 338). For the purposes of this study two additional types of activity are added. Traditional offices such as chiefs and leadership in revolutions or other anti-regime activity are also considered to be within the definition.

2. No single biographical directory contained the information on which this research is based. Instead, a wide variety of sources were consulted among which Current Biography and the New York Times were the most useful. A complete list is available on request.

3. Three other executives had office-holding relatives but are not included in this analysis. In one instance the leader's kinsman was a great grandparent. The other two cases are unique in that the executives are related to each other by marriage. President Omar Bongo of Gabon married the daughter of President Denis Sassou-Nquesso of the Congo. This marriage occurred when both men were already chief executives of their respective countries It is an interesting case because it is the only instance of a connection between executives from different states. Biographical data were derived from a wide variety of sources; a complete list of those sources and of the office-holding relatives of the executives is available to interested readers. At more than 50 pages, the list too extensive to include here.

4. This concept was developed and explained in an earlier article (Kurtz 1995,454 ) and is a variation the related concepts buman capital (Laband and Lentz 1983), and symbolic family estate (Farber 1971).

5. Major offices include the following: head of state or government, cabinet, national legislature, and the higher judiciary.

6. Two other papers, Kurtz 1996 and 1997c describe the families in more

\section{References}

Farber, Bernard. 1971. Kinship and Class: A Midwestern Study. New York: Basic Books.

Kurtz, Donn M. II. 1989. "The Political Family: A Contemporary View." Sociological Perspectives 32(Fall):331-52.

Kurtz, Donn M. 1995. "Inheriting A Political Career: The Justices of the United States and Louisiana Supreme Courts." The Social Science Journal 32(Number 4):441-457.

Kurtz, Donn M. II. 1996. "The Political Inheritance and Family Status of National Chief Executives." presented at the annual meeting of the Southwestern Political Science Association, Houston, TX.

Kurtz, Donn M. II. 1997a. "America's First Families: The Second Generation." National Social Science Journal 9(Number 2): 65-73

Kurtz, Donn M. II. 1997b. Kinship and Politics: The Justices of the United States and Louisiana Supreme Courts. Baton Rouge: LSU Press.

Kurtz, Donn M. II. 1997c. "Political Successions and Dynasties in the Modern World," International Journal of Contemporary Sociology 34(April):92-99.

Laband, David N., and Bernard F. Lentz. 1983. "Like Father, Like Son: Toward An Economic Theory of Occupational Following." Soutbern Economic Journal 50(October):474-93.

Prewitt, Kenneth. 1970. The Recruitment of Political Leaders: $A$ Study of Citizen-Politicians. Indianapolis: Bobbs-Merrill. 


\section{APPENDIX}

\section{Chief Executives, 1990}

* indicates politically active relative(s)

\section{Name}

Mohammad Najibullah*

Ramiz Alia

Chadli Bendjedid

Jose Eduardo dos Santos

Carlos Menem*

Robert James Lee Hawke*

Franz Vranitzky

Hussain Mohammad Ershad

Wilfred Martens

Mathieu Kerekou

Jaime Paz Zamora*

Q. K. J. Masire*

Fernando Collar*

Petur Mladevov

Blaise Compaore

Saw Maung

Pierre Buyoya

Hun Sen*

Paul Biya

Brian Mulroney

Andre Kolingba

Hissein Habre

Patricio Aylwin*

Deng Xiaoping*

Virgilio Barco Varga

Denis Sassou-Nguesso

Rafael A. Calderon*

Fidel Castro*

Vaclav Havel

Poul Schlueter

Country
Afganistan
Albania
Algeria
Angola
Argentina
Australia
Austria
Bangladesh
Belgium
Benin
Bolivia
Botswana
Brazil
Bulgaria
Burkino Faso
Burma
Burundi
Cambodia
Cameroon
Canada
CAR
Chad
Chile
China
Columbia
Congo
Costa Rica
Cuba
Czechoslovakia
Denmark

Joaquin Balaguer

Rodrigo Borja

Hosni Mubarak*

Alfredo Cristiana

Mengistu Haile Mariam

Mauno Koivisto

Francois Mitterand*

Omar

Alhaji Dawda Kairaba Jawara*

Lothar de Maiziere*

Helmut Kohl*

Jerry Rawlings*

Constantine Mitsotakis*

Mario V. Cerezo*

Lansana Conte

Joao Bernardo Vieira

Hugh Desmond Hoyte

Ertha Pascal-Trouillot*

Rafael L. Callejas

Jozef Antall*

V. P. Singh*

Thojib N. J. Suharto*

Ali Akbar Rafsanjani*

Saddam Hussein*

Charles Haughey*

Yitzhak Shamir

Guilio Andreotti

Felix Houphouet-Boigny*

Michael Manley*

Toshiki Kaifu

Daniel Arap Moi*

Kim II Song*

Tae Woo Roh

Kaysone Phomvihan*

Elias Hrawi*

Samuel Doe
Dom. Rep.

Ecuador

Egypt

El Salvador

Ethiopia

Finland

France

Gabon

Gambia

Germany, E

Germany, W

Ghana

Greece

Guatemala

Guinea

Guinea-Bissau

Guyana

Haiti

Honduras

Hungary

India

Indonesia

Iran

Iraq

Ireland

Israel

Italy

Ivory Coast

Jamaica

Japan

Kenya

Korea, N.

Korea, S.

Laos

Lebanon

Liberia 
Muammar Qaddafi

Didier Ratsiraka

Hastings Banda

Mahathir bin Mohamad

Mousa Traore

Maaouiya Ould Sid Ahmed Taya

Carlos Salinas*

Gombojaviin Ochiribat

Joachim Chissano

Sam Nujoma

Ruud Lubbers

Geoffrey Palmer

Violeta Chamorro*

Ali Saibu*

Ibrahim Babangida

Jan P. Syse

Benazir Bhutto*

Guillermo Endara

Rabbie Namilu

Andres Rodriguez

Alan Garcia Perez*

Corazon Aquino*

Wojciech Jaruzelski

Anibal Cavaco-Silva

Ion Iliescu

Juvenal Habyarimana

Abdou Diouf

Joseph Saidu Momoh

Lee Kuan Yew*

Mohamed Siad Barre*

F. W. De Klerk*

Felipe Gonzales

Ranasinghe Premedasa

Umar Hasan Ahmad Bashir

Ingvar Carlsson

Arnold Koller
Libya

Madagascar

Malawi

Malaysia

Mali

Mauritania

Mexico

Mongolia

Mozambique

Namibia

Netherlands

New Zealand

Nicaragua

Niger

Nigeria

Norway

Pakistan

Panama

Papua N.G.

Paraguay

Peru

Philippines

Poland

Portugal

Romania

Rwanda

Senegal

Sierra Leone

Singapore

Somalia

South Africa

Spain

Sri Lanka

Sudan

Sweden

Switzerland
Hafiz Assad*

Lee Teng-Hui

Ali Hassan Mwinyi

Chatchai Chunhawan*

Etienne Gnassingbe Eyadema

Zine el Abidine Ben Ali

Turgut Ozal

Yoweri Museveni

Margaret Thatcher*

George Bush*

Luis Alberto Lacalle*

Mikhael Gorbachev

Carlos Perez

Nguyen Van Linh

Ali Abdallah Salih

Haydar Abu Bakr al Attas

Ante Markovic

Mobutu Sese Seko*

Kenneth Kaunda

Robert Mugabe
Syria

Taiwan

Tanzania

Thailand

Togo

Tunisia

Turkey

Uganda

U. K.

U.S.

Uruguay

USSR

Venezuela

Vietiam

Yemen, $\mathrm{N}$.

Yemen, S.

Yugoslavia

Zaire

Zambia

Zimbabwe 